\title{
2006-1195: EVOLUTION OF THE ELECTRICAL POWER TECHNOLOGY PROGRAM AT THE UNIVERSITY OF HOUSTON
}

\section{Luces Faulkenberry, University of Houston}

\section{Wajiha Shireen, University of Houston}

Dr. Faulkenberry is an Associate Professor in the Engineering Technology Department of the University of Houston College of Technology and is the Coordinator of the Electrical Power Program.

Dr. Shireen is an Associate Professor in the Engineering Technology Department at the University of Houston College of Technology. She teaches and does research in electrical power. 


\section{Evolution of the Electrical Power Technology Program \\ at the \\ University of Houston}

\section{Abstract}

A revised Electrical Technology (ELT) program, now designated as Electrical Power Technology (EPTE), was started in the College of Technology at the University of Houston in 2003. The program will serve to not only electrical utilities, but also the large base of electrical contracting, equipment manufacturing, and sales companies in the Houston area. This paper will trace the steps taken by the faculty to change the program from Electrical Technology into the Electrical Power Technology program, and the steps that provided information for the resulting curriculum changes. The paper will also compare EPTE with other electrical and electrical power programs in the U.S.

The Electrical Technology program has been part of the former Electrical-Electronics Department for over fifty years, having been started prior to the first TAC-ABET (then ECPD) accreditation (around WW2). The program has experienced continuous change as technology has evolved over the years. Initially electrical technology was two separate programs. One was electrical power (EP) focusing on education related to electrical power transmission, distribution, and system design, and the other was control systems (CS) focusing on the applications of electronics and computers for analog and digital control in industry. Both programs eventually began to experience lower enrollment and difficulty in recruiting students. This situation worsened as with the increase of employment opportunities in computer-related areas. The department faculty decided to combine EP and CS into one major, called the Electrical Technology (ELT), with the same two areas of specialization. The more general Electronics Technology program was later was supplanted by the Computer Engineering Program. In spite of the relatively low enrollment the ELT major attracted enough students to continue even though the class sizes were sometimes fairly small.

The ELT major had a 14\% increase in majors from Spring 2000 to Spring 2001, which was encouraging, but the low total number of students remained a concern. After considerable consideration of the employment profiles in the Houston region and beyond, it was decided to de-emphasize the control systems aspect of the ELT program. Even though the Houston region has a massive petrochemical refining base, the refineries have shown some reluctance to hire baccalaureate level graduates from the control systems specialization, although they commonly employ associate degree instrumentation graduates. However, the job opportunities for electrical power graduates have been very good in the electrical power related industries through the years. The revised ELT curriculum, after considerable study and contact with industry, was redesigned to produce a strong electrical power technology program, which is now named the Electrical Power Technology (EPTE) program. The change has resulted in considerable increase in class sizes and numbers of majors. The new program now serves the large base of electrical contracting and equipment manufacturing companies in the Houston area as well as electrical utilities and independent power providers throughout Texas and beyond. 


\section{Brief History}

The University of Houston was founded in 1927 as Houston Junior College, and became a four year institution in 1934. In 1945 the University of Houston was separated from the Houston Independent School District and operated as a private university. The University of Houston became a state supported university in 1963, and by state law it became a state university system in 1997. (University of Houston, 2006) The College of Technology began in 1940 when a group of Houston industries donated money for the college building. The official opening of the college was in 1942. Initially the College of Technology offered two year degrees, offering 19 vocational and seven engineering technology programs (the first in Texas accredited by the ECPD) by 1945. The Electrical technology major was among the first majors offered in the former Electrical/Electronics Department. By 1968 the college was offering baccalaureate degrees. (College of Technology, 2006)

Initially the Electrical Technology major contained two different programs, Electrical Technology, which was electrical power related, and Instrumentation Technology, which focused on electronics and eventually computers for analog and digital control in industry (especially petrochemical). In time both programs began to experience lower enrollments as the computer industry became more pervasive and attractive to students. To increase program enrollment the two programs were merged into one major called Electrical Technology (ELT) with options in Electrical Power Technology (EPT) and Control Systems Technology CST) in the late 1980s.

\section{ELT Experiences}

Eventually, as computer use increased throughout all industries, both program options began to experience lower enrollment and difficulty in recruiting students. The lure of the expanding and exciting computer industry was understandable. Even with expanded computer use in Electrical Technology, at times the students in one or both options dropped low enough to make filling upper division classes, especially electives, difficult. This resulted in electives being offered less frequently to assure the classes had enough students to be offered.

On the positive side, about half of the ELT majors were working in the electrical or the control system field while pursuing their baccalaureate degree. This group of students normally already had an associate degree. While this resulted in a need for major classes to be offered as evening classes, the working students acted as very positive role models for the rest of the class. The working student also provided a great deal of tutoring for the class members without work experience in the electrical field. In addition placement was very good for graduates of both options. One anomaly in placement continued to be the fact that most control systems graduates went to work in manufacturing and very few directly into the petrochemical refining industry.

While the enrollment of ELT was enough to continue offering the program, the enrollment was about $1 / 4^{\text {th }}$ the enrollment of the Electronics Technology Program, which was later supplanted by the Computer Engineering Technology (CET) program. The ELT and the CET programs were both housed in the Electrical/Electronics Technology Department (ELET). 


\section{The Evolution Begins}

In 2000 the University of Houston administration hired a new Dean for the College of Technology. The new Dean believed that resources should go to more successful programs, with success defined primarily in program size. The Electrical Technology program was put on notice that is must position itself to grow.

The positioning process was accompanied by a great deal of discussion and brain storming by the entire faculty of the ELET department. The discussions revealed that the most support of the ELT major was from the electrical power industry, although the placement for both the program options was very good. The electrical faculty suggested that perhaps a more specialized program strongly oriented toward electrical power might be the way to expand and sustain enrollment. The electrical power industry was computerizing to an extent greater than it had before because of the control requirements by the necessary for a system as complex as the North American electrical grid, and the greater communications demands by both operational needs and the government. Additionally, the electrical power industry was getting more publicity, even if it was not all good. Thus the ELET department decided to investigate changing the Electrical Technology program into the Electrical Power Technology program with a curriculum aimed specifically at the electrical power industry.

Planning the change

The faculty, in consultation with some local industry representatives and the ELT Department board of industrial advisors prepared a list of major program curriculum areas. The program curriculum would contain coursework in the essential technical aspects of the industry including:

1. Generation,

2. Transmission and distribution,

3. Electrical machines and machine control (including PLCs as well as microprocessor controlled power semiconductor motor controls),

4. Electrical system protection emphasizing microprocessor based protection relays,

5. Electrical system design and project management,

6. The electrical industry practices and relationships,

The curriculum would emphasize the use of computers and software in the industry and electives in alternate energy systems, power semiconductor converters and power system communications were to be offered. The curriculum continues to contain mathematics through calculus II, a course in Laplace transforms, physics 1 and 2 with laboratories, a course in technical writing, a course in business practices, and a liberal arts university core curriculum. A new addition is a course in data bases at the request of electrical power technical and general managers in electrical power companies in the Houston area.

An internet search of electrical technology programs indicated that most do not offer such an indepth education in electrical power, but tend to offer a balance of about two to three courses each in electrical power and control systems, in addition to the normal basic electronics and computer courses. Only a very few baccalaureate degree granting schools, normally overseas, offer electrical programs that have a very high emphasis on electrical power. 
The next step was to refine and improve the curriculum plans with additional input from the ELET Department Industrial Advisory Board. The Board members were in agreement and offered some constructive suggestions. Local industries were visited and additional input sought. After that, two faculty members were scheduled to be at gatherings of a large number of electrical power industry professionals. They sought input from the gatherings and received approval and useful input. The next step was to send the planned program curriculum to industry representatives in companies in Texas and selected companies across the United States. The returns were encouraging, so the faculty packaged the topics into courses and began the approval process. The planning occupied the academic years 2000 and 2001.

\section{The Approval Process}

The first approval, after the ELET Department faculty approval was the informal approval of the Dean to allow the proposed Electrical Power Technology (EPT) major to go forward in the Fall semester of 2002. The proposal then went to and was approved by the College of Technology Academic Committee, and the university Undergraduate Council which also approved the program. In due course the University of Houston Administration and the State of Texas Higher Education Coordinating Board also approved the program. The new program became operational Fall 2003.

The Electrical Power Technology Program Results

The enrollment went from 91 in the Fall semester of 2003, which was up from about 60 the year before, to 109 for Fall 2003. These are not huge enrollment increases but they are not decreases and represent only one major, and one option, instead of two options. The interest from prospective students seems to have increased because the inquiries about the program have increased. The Electrical Power Program (now abbreviated EPTE because People Soft software needs four letters) is attracting a larger number of female students and freshmen who started at UH as well about the same number of transfer student who have attended community colleges. One change is the faculty have noticed is the need to present more information to the students in EPTE about industry, industry expectations, and types of jobs available as the percentage of students working in the electrical power industry has decreased. Over all, the electrical power faculty consider the outcome of the curriculum change to be quite positive. The number of students varies from about 80 to a little over 100 students over time as students graduate and new students start, but the junior and senior electrical power class size remains between 30 and 40 students.

The ELET Department name was changed to Engineering Technology Department in 2002 and now houses the Computer Engineering Technology, Construction Management Technology, Mechanical Technology, and Electrical Power Technology. The Electrical Power Technology and Mechanical Technology program sought and have had approval through the university Undergraduate Council name changes to Electrical Power Engineering Technology and Mechanical Engineering Technology respectively. This was sought to bring the nomenclature of these majors into alignment with the current naming practices of ABET accredited two and four year engineering technology programs. 


\section{Accreditation Experiences}

The ABET accreditation team visited in 2004 and evaluated the programs under the TC2K criteria. The preparation was long, often confusing in terms of evidence sought, and time consuming. The evidence preparation was very different than that of previous visits, involving more targeted evidence in smaller quantities than previous visits required. Finally, the visit was over and we found we had learned a great deal about assessment and continuous improvement as a result. In time the preliminary results arrived. All three programs up for accreditation were told to improve their continuous improvement processes, particularly in documenting the "close the loop" activities in which a noted problem solution is implemented.

A surprising recommendation in the preliminary report concerned the Mechanical Technology course in materials and manufacturing processes required by both Computer Engineering Technology and Electrical Power Technology. The evaluators for the two majors noted that the courses were not mentioned in the major objectives, and should be dropped or the objectives changed to indicate the need for the course. Electrical Power Technology faculty changed the objective to indicate the need for the course.

The final report resulted in all three programs receiving accreditation. The challenge is to keep the continuous assessment and improvement cycle in motion and truly continuous.

\section{Conclusions}

Looking back through the years, the Electrical Technology program, as are most technology programs, had been in constant evolution. The evolution resulted in improved courses and curriculum, but had not resulted in an identity and focus for the major that was attractive to very large group of students.

The faculty had already agreed a change was needed but could not decide on a course of action prior to the change order. Even though the timing of the evolution of the Electrical Technology program into the Electrical Power Technology program was not chosen by the department faculty, the results have been positive for the students, the faculty, and the electrical power industry in Texas. Student satisfaction with the program is high and job placement is very good. The department faculty and especially the electrical power faculty think the results have been very positive.

\section{Reference list}

1. College of Technology college videos. Retrieved January 10, 2006, from http://www.tech.uh.edu/college/explore/video.htm

2. University of Houston general information page. Retrieved January 10, 2006, from http://www.uh.edu/uh_glance/index.php?page=info 